\title{
KONSEP UMMAH DAN RAKYAT DALAM PANDANGAN ISLAM
}

\author{
Muhammad Faqih \\ UIN Sunan Ampel Surabaya \\ faqih2896@gmail.com
}

\section{Abstrak}

Tujuan penelitian ini ialah untuk mengetahui konsep ummah dan rakyat perspektif Islam yang sesungguhnya, apa saja kualifikasi-kualifikasi ummah dalam al-Qur'an Hadis, masyarakat madani, dan bagaimana konsep kewarga-negaraan dalam perspektif kajian Islam. Penelitian ini menggunakan pendekatan heuristik dan historiografi ala Notosusanto. Hasil penelitian yang diperoleh: ummah adalah suatu kumpulan masyarakat yang berbeda-beda baik suku, ras, agama, dan budaya yang memiliki visi-misi dan tujuan hidup bersama dalam merealisasikan perintah dan larangan Tuhan untuk kehidupan yang berkemajuan, bermartabat dan beradab. Konsep ummah dalam masyarakat madani adalah bermula pada proses hijrah Rasulullah Saw. yang diimplementasikan untuk memulai peradaban baru bersama masyarakat di Madinah. Konkretnya, Rasulullah Saw. meletakkan dasar-dasar masyarakat madani melalui bermusyawarah, dan merumuskan ketentuan dan tujuan hidup bersama yang meliputi kebebasan, keadilan, dan partisipasi. Dalam konsep kewarganegaraan Islam, ada dua penyebutan non-Muslim, yaitu kafir dzimmi dan musta'min. Kafir dzimmi merupakan warga non-Muslim yang memiliki kriteria seperti menetap di satu tempat selamanya, dihormati, dan jiwanya tidak boleh mendapat gangguan apapun. Dikatakan kafir dzimmi, maka individu tersebut mempunyai beberapa hak di antaranya hak kemanusiaan, hak sipil, dan hak politik. Adapun musta'min, mereka tidak memiliki hak-hak politik, karena mereka bagian dari orang asing.

Kata Kunci: Ummah, Rakyat, non-Muslim, Masyarakat Madani. 


\section{Abstract}

This study discusses the concept of the ummah and the people in Islamic perspective, what are the qualifications of the ummah in the Quran and Hadith, civil society, and how the concept of citizenship is in the perspective of Islamic studies. The research method used a heuristic and historiography approach according to Notosusanto. The result of the study showed that ummah is a group of people with different ethnicities, races, religions, and cultures that have a vision and mission and the goal of living together to realize God's commands and prohibitions for a progressive, dignified, and civilized life. The concept of the ummah in civil society originated in the process of the Prophet Muhammad's hijrah which was implemented to start a new civilization together with the people in the Medina. Concretely, Muhammad Saw. laid the foundations of civil society through deliberation, and formulated the terms and goals of life together which included freedom, justice, and participation. In the concept of Islamic citizenship, there are two terms of non-Muslim, namely kafir dhimmi and musta'min. Kafir dhimmi are non-Muslim citizens who have criteria such as staying in one place forever, being respected, and their souls should not be subject to any disturbance. Kafir dhimmi said that the individual has several rights including human rights, civil rights, and political rights. As for musta'min, they are individuals that do not have political rights, because they are part of foreigners.

Keywords: The People, Ummah, non-Muslims, Civil Society.

\section{Pendahuluan}

Pembahasan tentang keummatan dari zaman ke zaman seoalah tidak ada habisnya, tak terkecuali dari kalangan akademisi dan pemikir politik. Mereka berupaya untuk mendefinisikan konsep umat tersebut, yang sandingkan dengan konsep nation (bangsa) atau nation-state (negara-bangsa), tetapi pada akhirnya mereka dipersepsikan gagal dan kurang tepat dalam mendefinisikannya .

Konsep ummah (umat) sudah menjadi bagian dalam masyarakat. ${ }^{1}$ Meski

\footnotetext{
1 Muhammad Iqbal, Fiqh Siyasah: Konteks-
}

demikian, konsep tersebut masih sering dipahami secara keliru. Oleh karena itu, peneliti orientalis pun seperti W. Montgomery Watt dan Bernard Lewis menelaahnya secara mendalam. Di samping itu, Quraish Shihab juga telah menjelaskan bahwa kata ummah mengandung beragam keterangan yang cukup mendalam. Ummah memiliki substansi yang terdiri dari arah, waktu, gerak dinamis gaya dan cara hidup yang jelas. ${ }^{2}$ Maka

tualisasi Doktrin Politik Islam (Jakarta: Gaya Media Pratama, 2014).

${ }^{2}$ M. Quraish Shihab, Wawasan al-Qur'an: Tafsir Maudhu'i atas Pelbagai Persoalan Umat 
dari itu, untuk mencapai suatu arah harus memiliki jalan yang jelas disertai keharusan untuk bergerak maju dengan gaya dan cara tertentu, disaat bersamaan dibutuhkan waktu untuk mencapainya.

Artikel ini membahas secara terperinci dan mendalam terkait bagaimana konsep ummah dan rakyat dalam pandangan Islam yang sesungguhnya, apa saja kualifikasi-kualifikasi ummah dalam al-Qur'an dan Hadis, masyarakat madani, serta bagaimana konsep kewarganegaraan dalam perspektif Islam.

Dalam kajian ini akan digunakan suatu tahapan yang dikemukakan oleh Nugroho Notosusanto dalam bukunya, Norma-norma dalam Pemikiran dan Penulisan Sejarah, yaitu mencari atau menemukan sekaligus mengumpulkan jejak-jejak sejarah secara heuristik. Oleh karena itu, dalam kajian ini juga digunakan pendekatan penulisan sejarah atau istoriografi yang dilakukan berdasarkan pada fakta-fakta yang terjadi dan literature review yang ada. ${ }^{3}$

\section{Pembahasan}

\section{Konsep Ummah}

Dalam terminologi Islam, ummah merupakan suatu konsep yang menarik dan tidak terdapat dalam bahasa-bahasa

(Bandung: Mizan, 1996).

3 Eka Aprilia Permatasari, "Implementasi Pendekatan Saintifik dalam Kurikulum 2013 Pada Pembelajaran Sejarah," History Education 3, no. 1 (2014).
Barat. ${ }^{4}$ Pada awalnya, kalangan tokoh dari pemikir politik dan dari orientalis Barat mencoba untuk memberikan makna persamaan kata ummah dengan nation (bangsa) atau kata nation-state (negara-kebangsaan), tetapi persamaan ini tentu dianggap tidak sesuai sehingga pada akhirnya disesuaikan dengan kata community (komunitas). Namun, adanya istilah komunitas dengan ummah juga tidak terlalu tepat untuk disamakan. Abdul Rasyid Moten, Guru Besar Ilmu Politik Universitas Islam International Malaysia, menyatakan bahwa sangat sederhana apabila para pemikir memberikan persamaan kata ummah dengan komunitas.

Terdapat perbedaan prinsip antarkedua term ini, komunitas ialah sebuah kelompok masyarakat yang terbentuk dari perasaan yang sama, dan identitas komunal, serta persamaan budaya, wilayah, darah, suku atau kebangsaan, maupun dari semua penggabungan ini. Ummah diketahui bukan berdasarkan ras, budaya, bahasa, sejarah dan semua yang terkait dengan pembatasan wilayah atau biasa disebut wilayah geografis. ${ }^{5}$

Sifat universal dari $u m m a h^{6}$ berarti bahwa di antaranya kaum Muslim dapat dipersatukan ke dalam ikatan ideologi yang komprehensif dan kuat melalui

\footnotetext{
${ }^{4}$ Iqbal, Fiqh Siyasah: Kontekstualisasi Doktrin Politik Islam.

5 Iqbal.

6 Iqbal.
} 
Islam. Ummah diperlukan dalam mendukung aktualisasi dari apa yang dikehendaki Allah Swt. melingkupi ruang dan waktu untuk mencapai kehidupan yang bahagia di dunia dan di akhirat, atau bahkan dari semua gabungan ini. Adapun basis ummah tidak didasarkan pada ras, budaya, bahasa, sejarah atau gabungan dari semuanya dan tidak berbasis pada batas-batas wilayah geografis.

Ummah lebih dipahami sebagai entitas keagamaan yang terbebas oleh dimensi spasial nasionalisme dan teritorialisme. Sementara, di pihak lain, negara-bangsa justru mengukuhkan kelekatan entitas yang serba spasial, tetapi dimensi sosio-politik yang dituliskan sejarah tidak menggambarkan keharusan kesatuan sosio-politik yang bersifat tunggal dan justru al-Qur'an memberikan pandangan bahwa keragaman dan perbedaan sebagai hal yang positif bagi pembangunan manusia termasuk di dalamnya negara-bangsa. ${ }^{7}$

Pada intinya ummah mempunyai makna yang sangat luas, tetapi peneliti di sini akan memberikan sedikit penjelasan, bahwa ummah adalah suatu kumpulan masyarakat yang berbeda-beda baik suku, ras, budaya, dan sejarah yang memiliki tujuan hidup bersama guna menjalankan atau mengaktualisasikan kehendak-kehendak Allah dan disatu-

7 Zayad Abd Rahman, "Konsep Ummah dalam al-Qur'an: Sebuah Upaya Melerai Miskonsepsi Negara-Bangsa," Religi: Jurnal Studi Islam 6, no. 1 (2015): 1-18. kan melalui ideologi yang kuat dan komprehensif, yakni Islam.

\section{Konsep Ummah dalam al-Qur'an}

Selain syariah, ummah juga termasuk sumber kekuasaan politik. Kedaulatan dalam Islam tidak akan terwujud kecuali melalui kombinasi tiga unsur, yaitu syariah, ummah, dan khalifah. Arti penting ummah muncul di sepanjang al-Qur'an dan sejarah Islam. ${ }^{8}$

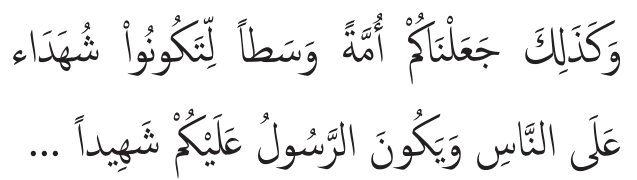

Dan demikian (pula) Kami telah menjadikan kamu (umat Islam), umat yang adil dan pilihan agar kamu menjadi saksi atas (perbuatan) manusia dan agar Rasul (Muhammad Saw.) menjadi saksi atas (perbuatan) kamu ... (QS. alBaqarah [2]: 143). ${ }^{9}$

Hal ini menempatkan ummah dan misi keagamaannya pada posisi penting dalam sistem politik Islam. Yang lebih penting dari itu ialah nilai tinggi yang terkandung adalah pelaksanaan keadi-

${ }^{8}$ Nur Mufid \& Nur Fuad, Bedah al-Ahkamus Sulthoniyah al-Mawardi (Surabaya: Pustaka Progresif, 2000).

9 Tim Penyusun Departemen Agama RI, Al-Qur'an dan Terjemahannya, Juz 1-30 (Semarang: PT. Kumudasmoro Grafindo, 1994). Selanjutnya pengutipan ayat al-Qur'an menggunakan rujukan ini. 
lan yang dipercayakan Tuhan kepada ummah. Tidak hanya itu, kedudukan ummah juga disinggung di dalam alQur’an:

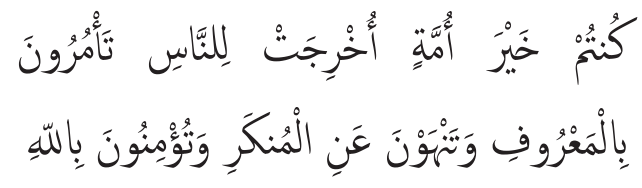

Kamu (umat Islam) adalah umat yang terbaik yang dilahirkan untuk manusia (karena kamu) menyuruh (berbuat) yang makruf, dan mencegah dari yang mungkar, dan beriman kepada Allah (QS. Ali Imran [3]: 110).

Imam al-Bukhori meriwayatkan dari Abu Hurairah mengenai ayat ini dijelaskan oleh beliau bahwa "Kalian adalah umat yang terbaik yang dilahirkan untuk manusia", dan ia berkata bahwa kalian bagian dari sebaik-baiknya manusia bermanfaat untuk manusia yang lainnya.

Dalam sejarah politik Islam, terdapat banyak pendapat dan tekanan yang berbeda-beda mengenai pentingnya ummah. Kaum Khawarij misalnya yang pertama membuat kaum Muslim memperhatikan sifat kharismatik dari masyarakat. Komunitas secara ideal dipahami sebagai penduduk surga, yang dibentuk oleh Tuhan. Doktrin ini merupakan salah satu ciri khas Khawarij. ${ }^{10}$

${ }^{10}$ Mufid \& Fuad, Bedah al-Ahkamus Sulthoniyah al-Mawardi.
Kaum Khawarij memandang diri mereka sebagai orang yang meninggalkan rumah dan kampung halamannya untuk mengabdikan diri kepada Allah dan Rasul-Nya. Kaum Khawarij kadang juga menyebut golongan mereka dengan kaum Syurah, kaum yang mengorbankan dirinya demi keridhaan Allah. ${ }^{11}$

Supaya terbentuk suatu hubungan yang harmonis antar-umat, para ulama telah mengadakan penelitian terhadap sejumlah aturan yang ada yang kemudian dikembalikan pada al-Qur'an dan Sunnah yang memunculkan kaidah alashlu fi al-'alaqah al-silm, yang pokok dalam hubungan ialah kedamaian. ${ }^{12}$

Selain itu, masih terdapat prinsipprinsip lain, seperti al-'adalah, karamah insaniyah, tasamuh, ta'awun, al-fadhilah, dan huriyah. Prinsip-prinsip ini kemudian memberikan warna atau corak tersendiri bagi kehidupan umat, baik umat dalam arti luas yaitu umat dalam artian makhluk Allah, maupun umat dalam arti sempit, yaitu umat sebagai komunitas agama tertentu.

\section{Konsep Ummah dalam Masyara- kat Madani}

Dalam kajian Islam, civil society

11 Saleh, "Khawarij: Sejarah dan Perkembangannya," El-Afkar: Jurnal Pemikiran Keislaman dan Tafsir Hadis 7, no. 2 (2018): 25-34, https://doi.org/10.29300/jpkth.v7i2.1597..

12 A. Djazuli, Fiqh Siyasah: Implementasi Kemaslahatan Umat dalam Rambu-rambu Syariah (Jakarta: Kencana, 2003). 
seringkali dipahami sebagai masyarakat madani atau ummah. ${ }^{13}$ Namun, secara umum, civil society lebih sering dihubungkan dengan kata ummah karena beberapa hal jika dilihat dari segi arti, ummah sendiri memiliki tiga makna yaitu:

1. Suatu golongan manusia (jama’ah).

2. Setiap kelompok manusia yang dinisbatkan kepada seorang Nabi.

3. Setiap generasi manusia sebagai satu umat.

Ali Syariati, seorang pemikir Muslim yang berfokus membahas pemikiran umat, berpendapat bahwa konsep umat memiliki keunggulan makna, yang terkait dengan arti kemanusiaan yang terus berkembang, bukan entitas kaku dan tetap. Menurutnya, umat terdri dari kata amma diartikan memiliki maksud dan suatu niat keras. ${ }^{14}$

Pengertian tersebut mengandung tiga unsur makna: gerakan, tujuan, dan ketetapan hati yang sadar. Masyarakat madani diartikan sebuah konsep kenegaraan yang menyatakan pada pemerintahan maupun negara pada zaman Rasulullah di Madinah. Maka dalam setiap kali rencana konsep ideal sistem

${ }^{13}$ M. Ihsan Dacholfany, "Konsep Masyarakat Madani dalam Islam," Akademika: Jurnal Pemikiran Islam 17, no. 1 (2012): 47-74, https://doi.org/10.32332/ akademika.v17i1.213.

${ }^{14}$ Ali Syariati, Ummah \& Imamah: Suatu Tinjauan Sosiologis (Bandung: Pustaka Hidayat, 1989). kenegaraan terutama kaitannya dengan Islam didiskusikan, selanjutnya orang akan selalu merepresentasikan pemerintahan atau konsep negara saat zaman Rasulullah di Madinah.

Dalam sejarah diceritakan bahwa setelah hampir 13 tahun Nabi membangun landasan tauhid sebagai pondasi dasar masyarakat (Makkah), Allah Swt. memberikan petunjuk agar hijrah ke Yastrib. Setelah itu, Nabi mengganti nama Yastrib menjadi Madinah, yang bermakna kota. Tindakan Nabi mengubah nama Yastrib menjadi Madinah sebagai sebuah pernyataan sikap atau proklamasi bahwa bersama umatnya hendak mendirikan dan membangun masyarakat yang beradab.

Berawal dari itu nabi bersama penduduk Madinah secara konkret meletakkan dasar-dasar masyarakat madani dengan bermusyawarah dan merumuskan kebijakan dan tujuan hidup bersama yang meliputi kebebasan, keadilan, dan partisipasi yang dikenal dengan Piagam Madinah. ${ }^{15}$ Ketentuan ini berlaku bagi semua unsur masyarakat tanpa membedakan suku, ras, dan agama.

Nabi Muhammad Saw. datang ke Madinah untuk melakukan komunikasi terkait dengan risalah dan perubahan. Beliau memberikan pengajaran tentang penghapusan kelas di antaranya orang

${ }^{15}$ Luqman Rico Khashogi, "Konsep Ummah dalam Piagam Madinah," In Right: Jurnal Agama dan Hak Asasi Manusia 2, no. 1 (2017). 
kaya, dan miskin, golongan pengusaha dan buruh, golongan rakyat kecil dan pejabat. Rasulullah Saw. saat itu menekankan pada hubungan saling mengasihi, menyantuni yang membutuhkan dan hubungan persaudaraan.

Bnetuk Negara pada masa Rasulullah berbentuk teokratis, sedangkan pada masa Khulafaur Rasyidin lebih kepada republik demokratis. Setelah masa Khulafaur Rasyidin bentuk negara seringkali berubah-ubah sesuai dengan perkembangan zaman.

Mencuatnya beragam bentuk, pola maupun model negara karena memang tidak diatur secara tetap di dalam alQur'an dan Hadis. Di dalam al-Qur'an hanya menggarisbawahi bahwa umat Islam agar selalu taat kepada Allah, Rasul-Nya, dan pemimpinnya. Dengan kata lain, umat Islam diperintahkan agar menerapkan hukum-hukum yang bersumber dari al-Qur'an dan Hadis. Seperti halnya di Madinah, Rasulullah Saw. juga menerapkan hukum-hukum Islam kepada umat Islam serta sanksisanksinya. Namun, dalam hubungan ketatanegaraan dan kewarganegaraan yang terdiri dari beragam etnis, kabilah, dan agama (kepercayaan), maka Rasulullah sebagai kepala negara dan pemerintahan menerapkan dan memutuskan aturan-aturan yang dapat mencakup dan mengikat perbedaan-perbedaan tersebut - ini yang kemudian kita kenal dengan Piagam Madinah.

\section{Kewarganegaraan dalam Islam}

Dalam telaah pemikiran modern, negara adalah gabungan rakyat yang menempati wilayah tertentu dan patuh pada kekuasaan atau sistem pemerintahan tertentu. Telaah ini memberikan batasan bahwa unsur suatu negara terdiri dari tiga hal, yakni: 1) rakyat atau kumpulan individu, 2) wilayah, dan 3) pemerintah.

Dalam pengertian ketatanegaraan konvensional, rakyat sendiri berasal dari dua unsur, yaitu 1) unsur materil adalah gabungan orang yang menetap secara mapan atau kekal di wilayah tertentu dan 2) unsur spiritual (maknawi) adalah keinginan atau maksud bertempat tinggal dan hidup bersama dan dengan tujuan yang sama. ${ }^{16}$

Konsep kewarganegaraan Islam dibagi menjadi dua, yaitu Muslim dan non-Muslim. ${ }^{17}$ Non-Muslim sendiri ada yang disebut dzimmi dan ada beberapa yang disebut musta'min. Kafir dzimmi merupakan warga non-Muslim yang menetap abadi, serta dihormati dan tidak boleh diganggu jiwa, kehormatan,

\footnotetext{
${ }^{16}$ Dadang Suprijatna, "Constitutional Convention in Practice Constitution in Indonesia," Jurnal Hukum De'rechtsstaat 1, no. 1 (2015): 1-10, https://doi.org/10.30997/jhd.v1i1.394.

${ }^{17}$ Fandy Adpen Lazzavietamsi et al., "Pemikiran Politik Kyai dalam Kewarganegaraan Indonesia," Jurnal Moral Kemasyarakatan 4, no. 2 (2019): 46-54, https://doi.org/10.21067/ jmk.v9i2.4055.
} 
dan harta. ${ }^{18}$ Kafir dzimmi memiliki hak kemanusiaan, hak sipil, dan hak politik. Berbeda dengan musta'min yang tidak memiliki hak politik, karena mereka adalah orang asing. Akan tetapi, persamaannya adalah mereka non-Muslim.

Dalam konsep kewarganegaraan tentunya ada hak-hak dan kewajiban rakyat, Abul A'la al-Maududi menyatakan bahwa hak-hak rakyat sebagai berikut:

1. Perlindungan terhadap hidupnya, hartanya, dan kehormatannya.

2. Perlindungan terhadap kebebasan pribadi.

3. Kebebasan menyatakan pendapat dan berkeyakinan.

4. Terjamin kebutuhan pokok hidupnya, dengan tidak membedakan kelas dan kepercayaannya. ${ }^{19}$

Dari penjelasan tersebut, dapat diketahui bersama bahwa masalah hak ini termasuk wilayah ijtihadiyah. Artinya, hak mempunyai korelasi dengan kewajiban; sedang hak dan kewajiban tidak dapat kita pisahkan satu sama lain. Misalnya, seorang imam mempunyai

${ }_{18}$ Tri Handoko, "Kafir Dzimmi: Orang Kafir di Negeri Islam," Kompasiana (2015), https:// www.kompasiana.com/komentar/tryhandoc o/5520603fa333117c4646ce2c/kafir-dzimmiorang-kafir-di-negeri-islam (accessed Agustus $25,2020)$.

${ }^{19}$ Riska Muazzinah, "Konsep Demokrasi: Studi Komparatif antara Pemikiran Abul A’la al-Maududi dan Praktiknya di Indonesia," Disertasi (UIN Ar-Raniry, 2019). hak, yaitu untuk ditaati dan dipatuhi dalam menjalankan program kerjanya secara sadar dan bertanggung jawab. Maka kewajiban seorang rakyat adalah taat dan membantu serta berperan aktif dalam melaksanakan program-program yang telah disepakati bersama untuk mewujudkan kemaslahatan bersama.

Di dalam Islam hak asasi manusia (HAM) bukan sekadar diakui, tetapi juga mendapatkan perlindungan sepenuhnya. Prinsip tersebut secara global ditegaskan dalam QS. al-Isra' [17]: 70, dijelaskan bahwa anak cucu Adam ialah ciptaan-Nya yang memiliki kemuliaan. Kemuliaan itu yang kemudian dispesifikasikan oleh Hasby menjadi tiga kategori: 1) kemuliaan pribadi, 2) kemuliaan masyarakat, dan 3) kemuliaan politik. ${ }^{20}$

Pertama, kemuliaan pribadi, artinya bahwa manusia sebagai makhluk Allah dilindungi baik pribadi maupun hartanya. Kedua, kemuliaan masyarakat, manusia harus mempunyai status persamaan dan dijamin sepenuhnya. Ketiga, kemuliaan politik, berarti bahwa hakhak politik menjamin sepenuhnya bagi setiap warga negara.

Adapun hak-hak warga negara yang diakui di dalam Islam antara lain dari hak beragama, hak hidup, hak berpikir,

${ }^{20}$ John Kenedi, "Prostitusi dalam Perspektif Hak Asasi Manusia dan Islam: Studi Kasus Praktik Prostitusi di Kota Bengkulu," Jurnal Ilmiah Mizani: Wacana Hukum, Ekonomi dan Keagamaan 4, no. 1 (2018): 1-8, https://doi. org/10.29300/mzn.v4i1.1003. 
dan hak untuk berpendapat, serta hak setara dalam hukum (equality before the law).

\section{Simpulan}

Dengan demikian, konsep ummah merupakan suatu masyarakat yang berbeda-beda baik suku, ras, agama dan budaya yang mempunyai visi-misi dan tujuan hidup bersama untuk merealisasikan perintah dan larangan Tuhan untuk kehidupan yang berkemajuan, bermartabat dan beradab.

Konsep ummah dalam masyarakat madani bermula ketika Rasulullah Saw. hijrah dari Makkah ke Madinah atas kehendak Allah untuk memulai suatu kehidupan baru. Bersama-sama dengan penduduk Madinah, Rasulullah secara nyata meletakkan asas-asas masyarakat madani seperti musyawarah dan merumuskan ketentuan dan tujuan hidup bersama yang meliputi kebebasan, keadilan, dan partisipasi.

Dalam konsep kewarganegaraan secara dibedakan menjadi dua: Muslim dan non-Muslim. ${ }^{21}$ Non-Muslim dibagi menjadi kafir dzimmi dan musta'min. Kafir dzimmi adalah warga non-Muslim yang menetap mutlak, serta dihormati dan tidak boleh diganggu jiwa, harta,

21 Idil Akbar, "Khilafah Islamiyah: Antara Konsep dan Realitas Kenegaraan (Republik Islam Iran dan Kerajaan Islam Arab Saudi)," Journal of Government and Civil Society 1, no. 1 (2018): 95-109, https://doi.org/10.31000/jgcs v1i1.265. dan kehormatannya. Kafir dzimmi mendapat hak-hak kemanusiaan, hak-hak sipil, dan hak-hak politik. Sebaliknya, musta'min tidak memiliki hak-hak politik karena mereka adalah orang asing.

\section{Daftar Pustaka}

Akbar, Idil. "Khilafah Islamiyah: Antara Konsep dan Realitas Kenegaraan (Republik Islam Iran dan Kerajaan Islam Arab Saudi).” Journal of Government and Civil Society 1 , no. 1 (2018): 95-109. https://doi. org/ 10.31000/jgcs.v1i1. 265.

Dacholfany, M. Ihsan. "Konsep Masyarakat Madani dalam Islam." Akademika: Jurnal Pemikiran Islam 17, no. 1 (2012): 47-74. https:// doi.org/10.32332/akademika. v17i1.213.

Handoko, Tri. "Kafir Dzimmi: Orang Kafir di Negeri Islam.” Kompasiana, 2015. www.kompasiana. com/komentar/tryhandoco/55 20603fa333117c4646ce2c/kafirdzimmi-orang-kafir-di-negeriislam (accessed Agustus 25, 2020).

Iqbal, Muhammad. Fiqh Siyasah: Kontekstualisasi Doktrin Politik Islam. Jakarta: Gaya Media Pratama, 2014.

Kenedi, John. "Prostitusi dalam Perspektif Hak Asasi Manusia dan Islam: Studi Kasus Praktik Prostitusi di Kota Bengkulu.” Jurnal Ilmiah Mizani: Wacana Hukum, Ekonomi 
dan Keagamaan 4, no. 1 (2018): 1-8. https://doi.org/10.29300/ mzn.v4i1.1003.

Khashogi, Luqman Rico. "Konsep Ummah dalam Piagam Madinah.” In Right: Jurnal Agama dan Hak Asasi Manusia 2, no. 1 (2017).

Lazzavietamsi, Fandy Adpen, et al. "Pemikiran Politik Kiai dalam Kewarganegaraan Indonesia.” Jurnal Moral Kemasyarakatan 4, no. 2 (2019): 46-54. https://doi.org/10. 21067/jmk.v9i2.4055.

Muazzinah, Riska. "Konsep Demokrasi: Studi Komparatif antara Pemikiran Abul A'la al-Maududi dan Praktiknya di Indonesia.” Disertasi. UIN ar-Raniry, 2019.

Mufid, Nur \& Nur Fuad. Bedah alAhkamus Sulthoniyah al-Mawardi. Surabaya: Pustaka Progresif, 2000.

Notosusanto, Nugroho. Norma-Norma dalam Pemikiran dan Penulisan Sejarah. Jakarta: Departemen Pertahanan dan Keamanan, 1988.

Permatasari, Eka Aprilia. "Implementasi Pendekatan Saintifik dalam Kurikulum 2013 pada Pembelajaran Sejarah." History Education 3, no. 1 (2014).

Rahman, Zayad Abd. "Konsep Ummah dalam al-Qur'an: Sebuah Upaya Melerai Miskonsepsi NegaraBangsa." Religi: Jurnal Studi Islam 6, no. 1 (2015): 1-18.
Saleh, Saleh. "Khawarij: Sejarah dan Perkembangannya." El-Afkar: Jurnal Pemikiran Keislaman dan Tafsir Hadis 7, no. 2 (2018): 25-34. https:// doi.org/ 10.29300/jpkth.v7i2.1597.

Shihab, M. Quraish. Wawasan Al-Qur'an: Tafsir Maudhui atas Pelbagai Persoalan Umat. Bandung: Mizan, 1996.

Syariati, Ali. Ummah \& Imamah: Suatu Tinjauan Sosiologis. Bandung: Pustaka Hidayat, 1989.

Suprijatna, Dadang. "Constitutional Convention in Practice Constitution in Indonesia." Jurnal Hukum Dérechtsstaat 1, no. 1 (2015): 1-10. https://doi.org/10.30997/jhd.v1i1. 394.

Tim Penyusun Departemen Agama RI. Al-Quran dan Terjemahannya, Juz 1-30. Semarang: PT. Kumudasmoro Grafindo, 1994. 